Research Article

\title{
Research on the New Model of Aerobics Physical Education under the Background of Artificial Intelligence Era
}

\author{
Yi Liu \\ China University of Mining \& Technology, Beijing, China \\ Correspondence should be addressed to Yi Liu; qwertyuiop242021@126.com
}

Received 24 September 2021; Revised 19 October 2021; Accepted 19 November 2021; Published 8 December 2021

Academic Editor: Omar Cheikhrouhou

Copyright (c) 2021 Yi Liu. This is an open access article distributed under the Creative Commons Attribution License, which permits unrestricted use, distribution, and reproduction in any medium, provided the original work is properly cited.

This study aims to investigate and analyze the use of a new model of teaching physical education in higher learning institutions. Most traditional methods entail the instructor-based approach, which might not be appropriate to derive all the benefits and restore sanity in college and university students' health status. A new model is thus imminent that will be able to place the student at the center of the entire activity. Self-motivation is the most critical intrapersonal skill needed to ensure continual improvement. Developing a model that will oversee the development of self-motivation is thus essential. In this study, future research was conducted based on the previous literature on the best model for PE. The acquired data were then presented graphically, discussions were derived, and conclusions were ensued.

\section{Introduction}

Inactivity has been found to have negative repercussions on health [1]. Lack of physical activity does not only cause immediate and acute effects on the individual but it can also cause ramifications throughout the individual's lifespan. This can be detrimental as far as the individual's health status is concerned. Fostering physical education among adolescents is believed to cause a positive effect throughout adulthood since it facilitates its continuation. The opposite can be said for physically inactive adolescents, who grow into physically incapacitated adults. Chronic noncommunicable infections such as obesity and hypertension are known to increase with a lack of rigorous activities. Research has indicated that almost two-thirds of the global population is either overweight or obese. This owes to the lack of a better approach to physical education, especially in learning institutions. Obesity, defined as weight corrected for height, is prevalent. It is the measure of an individual's weight in kilogram per the square height of the individual. A formula used to derive the body mass index (BMI) can quantify if an individual is obese. BMI [2] can be calculated using the formula in equation (1). Obesity refers to a certain degree of obvious overweight and too thick fat layer. It is a state caused by excessive accumulation of fat, especially triglycerides. Excessive fat accumulation in the body due to excessive food intake or changes in body metabolism results in excessive weight gain and human pathological and physiological changes or latent diseases. Evaluation criteria are as follows: obesity $=($ actual weight - standard weight $) \div$ standard weight $\times \pm 100 \%{ }^{\circ}$ Weight loss methods include the following: enema weight loss method, osmotic pressure weight loss method, sauna weight loss method, milk powder weight loss method, rope skipping weight loss method, and Pu'er tea weight loss method.

$$
\operatorname{BMI}\left(\frac{\mathrm{Kg}}{\mathbf{m}^{2}}\right)=\frac{\text { mass }(\text { kilograms })}{\text { height }^{2}(\text { meters })} \text {. }
$$

Table 1 indicates the reference ranges for which someone can be considered either underweight or overweight based on their BMI and an average $5^{\prime} 9^{\prime \prime}$ height.

Research has shown that physical fitness helps keep cholesterol levels in check that prevents the possibility of acquiring obesity and the other NCD counterparts. The mechanisms are well documented in the previous literature. Low-density lipoproteins (LDLs) and apolipoproteins, particularly apolipoprotein $\mathrm{B}$, have been correlated with the 
TABLE 1: BMI reference ranges and the corresponding underlying condition.

\begin{tabular}{lccc}
\hline Height & Weight range & BMI & Considered \\
\hline & 124lbs or less & Below 18.5 & Underweight \\
$5^{\prime} 9^{\prime \prime}$ & 125 lbs to 168 lbs & 18.5 to 24.9 & Healthy weight \\
& 169lbs to 202 lbs & 25.0 to 29.9 & Overweight \\
& 203 lbs or more & 30 or higher & Obese \\
& 271 lbs or more & 40 or higher & Class 3 obese \\
\hline
\end{tabular}

development of cardiovascular infections such as chronic heart disease (CHD). As physical activity prevents the buildup of triglycerides (TAGs), it helps reduce the chances of these CVD-related complications. PA mostly reduces TAGs and apolipoprotein B while increasing the highdensity lipoprotein (HDL) [3], commonly known as the good cholesterol. Longitudinal studies have indicated the reduction of apo-B by almost $20 \%$. The causes of obesity include genetic and environmental factors, changes in material metabolism and endocrine function, increase and hypertrophy of adipocytes, neuropsychiatric factors, life and eating habits, drug-induced obesity, intestinal problems, and unabsorbable residues.

A recent study conducted by Carrol et al. indicated that aerobic endurance training conducted for approximately 45 minutes, three days a week, can increase HDL by $0.05 \mathrm{mmol} / \mathrm{L}$; with a $95 \%$ confidence interval, the increase can be in a range of 0.03 to $0.06 \mathrm{mmol} / \mathrm{L}$. On the other hand, TAGs have the potential to be decreased by $0.21 \mathrm{mmol} / \mathrm{L}$, with a $95 \%$ confidence interval; the reduction can be in the range of 0.14 to 0.29 . A meta-analysis trial conducted on an obese individual for eight weeks' duration of time shows that there is a likelihood of an $11 \%$ decrease in TAGs with AET. Another prospective cohort study conducted on overweight individuals also concluded the importance of PA on individuals' lifestyles. This particular study was conducted with 100 participants for 14 weeks' duration. The criteria for selection were a BMI of the range $25-30 \mathrm{~kg} / \mathrm{m}^{2}$. The 100 individuals were randomly selected with the selection criterion in mind, after which they were divided into different groups, each of which was to be taken through some form of activity throughout the 14 weeks' duration [4]. The first group was involved in performing rigorous training under the supervision of an instructor who was to take them through a one-hour session daily for the entire 14 weeks' duration. Note that aerobic endurance is also known as aerobic capacity. It refers to the working ability of aerobic energy supply for a long time. The load intensity is $75 \% \sim 85 \%$ of the maximum load intensity of the human body, and the heart rate is generally $110 \sim 150$ beats/min. The time shall be at least 5 minutes, generally more than 15 minutes. The physiological factors that determine the body's aerobic endurance are mainly the supply of oxygen during exercise and the content of glycogen as an energy substance.

On the other hand, the second group was to be involved in rigorous activities without the instructor's supervision. This meant that they were not under any tight schedule, and thus they could choose any form of exercise that they found fit. The third group was the control group who did not receive any intervention in the form of PA. Table 2 shows the division and description of each group for this particular study. The continuous load method is the main method to develop aerobic endurance. It is characterized by large load and no intermission. The continuous load method can be divided into constant speed training and variable speed training according to whether the speed changes or not. When the continuous load method is adopted for training, each load time shall not be less than 30 minutes. For athletes with a certain training level, the load time can reach 60 120 minutes. The exercise intensity can be calculated by measuring the heart rate, which can be controlled at 150 170 times per minute.

For group 1, there was a tremendous quantitative improvement in their BMI after the activity. They were kept under a tight schedule, which warranted them to always participate in the AET activities. This is opposed to the other groups. Although there was a slight reduction in BMI for individuals in group 2, it was not quantifiable in group 1 individuals. Lack of supervision may have led to engagement in nonrigorous activities or inconsistent turn-ups [5]. The third group was the negative control group with no intervention, and thus there was no change in BMI or any parameter analyzed. The results of this study are summarized in the graph in Figure 1.

It should be noted that negative and positive controls are for "expected results." The group with certain expected results is the positive control group. The group that certainly will not have the expected results is the negative control group. Blank control refers to "treatment factors." The group without treatment factors was the blank control group. Negative control and blank control may not be equal. The difference between the two is that the blank control does not add treatment factors, and the negative control adds other treatment factors.

As indicated in graph 1, there was a decrease in BMI by 3.8 for group 1 instead of 0.8 for group 2. There was no change for the negative control as indicated on the graph.

This goes without saying that notwithstanding the numerous benefits of physical education curriculum in higher institutions of learning, an appropriate model must be put into place to ensure that both the instructors and students reap the help of this acidity in their curriculum [6]. It is the only way to assure a right to live as far as leading a healthy life is concerned. In the subsequent sections of this research study, we will be looking into the development of the right model for colleges and universities as far as physical education and its curriculum are concerned. We will be proposing a model that will oversee self-determination, selfmotivation, and self-regulation aspects in the learning process. Unless the trainees are self-driven and motivated, physical education will be the other theoretical lesson in institutions. It will just be taken with a grain of salt and taught the same way philosophy is taught [7]. This will be harmful to this generation, and the rest that is to come.

Physical education undergraduate majors cultivate allround development of morality, intelligence, physique, and beauty, have a high sense of social responsibility, good scientific, and cultural literacy, have modern education and 
TABLE 2: Divisions of participants involved in AET.

\begin{tabular}{lccc}
\hline Groups & Group 1 & Group 2 & Group 3 \\
\hline Description & Rigorous activity under the supervision of an instructor & Rigorous activity with no supervision & Control group \\
\hline
\end{tabular}

AET BMI Changes on the 3 Groups

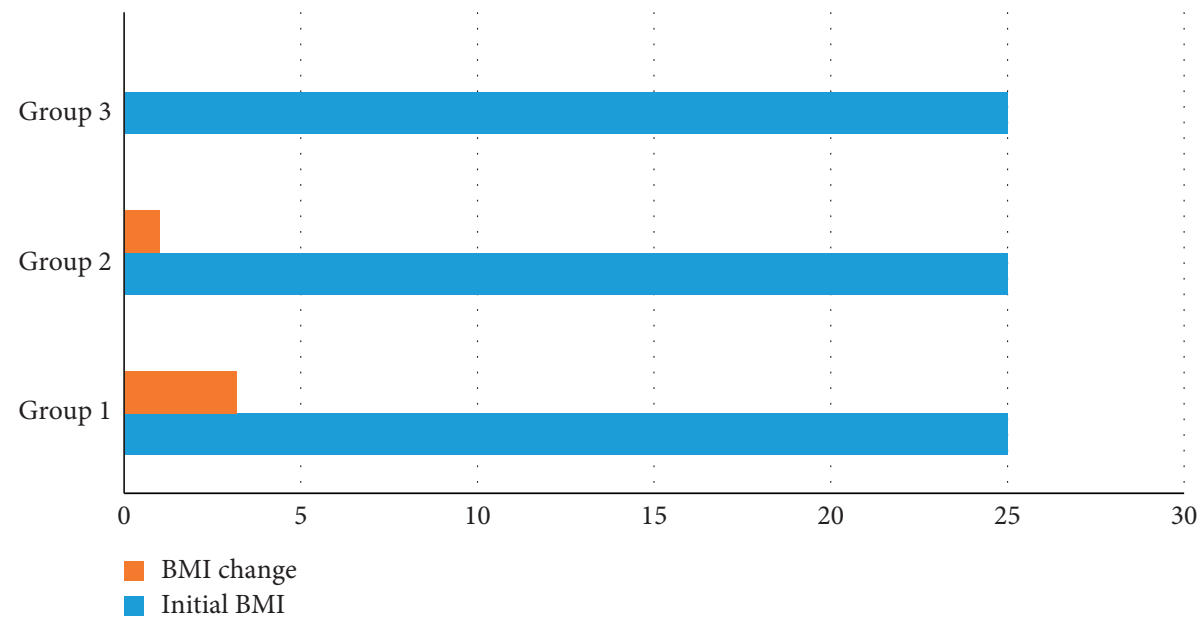

Figure 1: Graph on BMI improvements within 14 weeks' duration of AET activity.

health concepts, systematically master the basic theories, basic skills, and basic methods of physical education, have innovative spirit, and have certain physical education scientific research ability and entrepreneurial consciousness. Students with talents can apply entrepreneurial abilities and qualities, which enables them to participate in mass and competitive sports.

\section{Method}

One hundred and ninety-five participants were randomly selected for this study. The criterion for selection was that they had to be college students with an average adult height, approximately 5 feet 9 inches tall. The sample size was calculated using the formula as follows:

$$
\mathbf{n}=\frac{(\mathbf{T} \times \mathbf{T}) \mathbf{p}(1-\mathbf{p})}{b^{2}}
$$

where $\mathbf{n}$ is the sample size, $\mathbf{T}$ is the SD for $95 \% \mathrm{CI}, \mathbf{p}$ is the known proportion, and $\mathbf{b}$ is the desired precision level

$$
\mathbf{n}=\frac{\left(1.96^{2}\right) 0.85(1-0.85)}{0.05^{2}}=195 \text { participants. }
$$

A survey study was then conducted on the participants. They were asked to provide anonymous responses on how traditional models were infringing on their autonomy, motivation, leisure time, climate, and competence. This survey was conducted before their scheduled physical education lesson. For autonomous infringement, a questionnaire was prepared with six subscales that the students were to identify with. The six subscale items were in the qualitative range of autonomous to pawn [8]. Autonomous is where the students have the freedom to choose the activity they are to engage in; in other words, they have a say in whichever activity they are involved in. On the other hand, the pawn means that the instructor holds all the cards appertaining to the activities that are to be conducted. The subscale questions are as indicated in Table 3 with their corresponding range numbers. Besides, confidence interval refers to the estimation interval of population parameters constructed by sample statistics. In statistics, the confidence interval of a probability sample is the interval estimation of a population parameter of the sample. The confidence interval shows the degree to which the real value of this parameter has a certain probability to fall around the measurement results. It gives the degree of confidence of the measured value of the measured parameter, that is, the "one probability" required earlier. Confidence interval is a commonly used interval estimation method. The so-called confidence interval is an interval composed of the upper and lower bounds of the statistics.

Based on the above scoreboard, $95 \%$ of the students chose item 6 with the $1 / 6$ score on autonomy. This is because the traditional model is instructor-centered and lacks the qualities mentioned above of a good learning model. A good model should be one that puts the student at the center of learning. The student is, in turn, self-driven and self-motivated toward the activities in question. Only $1.3 \%$ of the students voted for the first item for traditional PE teaching models. $3.7 \%$ of the rest chose items 2,3 , 4, and 5 . However, their responses were not quantifiable as the conclusion on the ineffective traditional models had already carried the day. Since the study's findings could not be done using just the autonomy aspect, we investigated even motivation that the student presented within the course of PE with traditional models. This was done using open-ended questionnaires from which the students were to give open-ended 
TABLE 3: Sun-scale items for measuring origin (autonomous) motivation.

Item Autonomous score

Instructor allows you to explore new ways of doing things 6

The instructor provides peer students to assist the ones who have no understanding of the activities

The instructor helps the student who does not know of the activity

5

Both the instructor and the trainee make decisions

4

Only the instructor's findings are upheld

The rules are made to favor the instructor

answers on their experience with conventional PE models. For instance, the questionnaire could present a question in the form "During the PE lesson....," allowing the student to enumerate what motivated him/her in the course of the entire PE activity. Perceived competence and relatedness qualities were also investigated using the same questionnaires for the motivation assessment. The findings of the study indicated a negative relationship between selfmotivation, autonomy, competence, and traditional $\mathrm{PE}$ teaching models. The graph in Figure 2 shows the relationship between these qualities and traditional teaching models [9].

Besides, the characteristics of open-ended questionnaire are that there is no strict structural form in the setting and arrangement of projects, the questions investigated are open, and the respondents can express their opinions and views according to their own wishes. However, the open-ended questionnaire has a structure that is lax and inconsistent. The advantage is that a wide range of data can be collected. We can deeply discover and explore some special problems and inquire into the opinions and views of special groups. The disadvantages are as follows: the collected data are difficult to quantify and for statistical analysis. Researchers are required to have strong ability of data analysis. It is not suitable for research objects with low educational level and difficult written expression.

Figure 2 indicates a negative correlation observed with traditional physical education teaching models. There is a lack of motivation, autonomy, competence, and relatedness.

The graph in Figure 2 shows a negative correlation. This calls for a new teaching model that might incorporate all these qualities and translate the process of learning from instructor-centered to a student-centered approach. The new model, the student-centered approach model (SCAM), was developed for this sole purpose. This SCAM method employed a student-centered approach. The technique gave students the autonomy to perform their choice activity under the instructor's supervision, unlike the traditional system where the instructor made all the decisions. For instance, daily, a student was asked to select a physical activity after which he/she could demonstrate to ensure the other students were at par and fully understood the nature of the action. A curriculum was created with the names of students and the day they were to select an activity. This activity was conducted for a certain period after which qualitative and quantitative data were taken.

For this activity, the students were to enumerate how their experience has been throughout the period and the impact the study had on their self-motivation. An

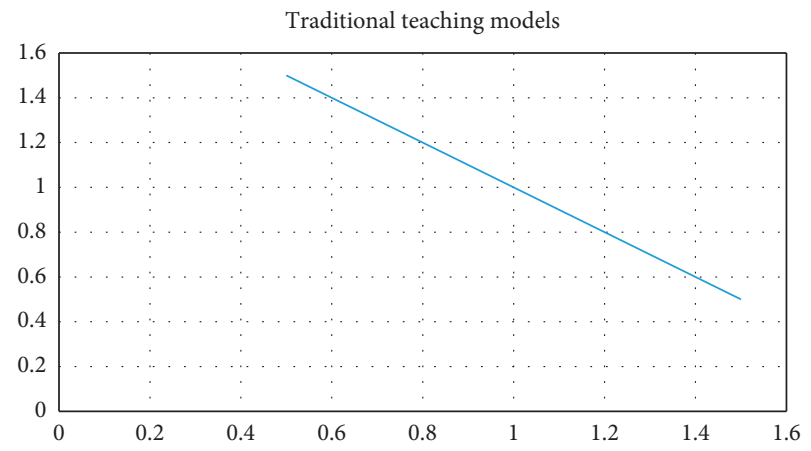

FIGURE 2: Relationship between traditional teaching models and autonomy, competence, motivation, and relatedness.

open-ended questionnaire was used for this purpose. Most of the participants reported that the activities had a positive effect on them. They explained that this was because they were peer-derived, making it look more autonomous than the standard pawn traditional models. Many even reported that they had learned a lot from their peers within the short period than they have even learned throughout their entire physical education curriculum. Since the activities were selfdriven, a positive result was also indicated in their overall BMI. The study was conducted within 14 weeks, after which $98 \%$ of the students have a recognizable change in their overall body weight. The remaining $2 \%$, on the other hand, had not experienced any change in their body weight. Moreover, they had also reported the importance of peer-topeer learning throughout the activity.

To assess the students' understanding, the use of $21^{\text {st }}$-century assessment criteria was applied. Some of the tools that were used were rubric and peer review. This was to ensure that even though there was autonomy in the activity selection, the activity's purpose was not lost. A rubric was prepared, indicating the various steps to be taken and the milestone to be hit within a stipulated time [10]. For instance, if the students were to perform AET, all the steps were indicated on the rubric. For peer review, a fellow student was to give comments on the exercise and access the other students. This activity was also done the same way selection was made, in which a schedule was created for every participant indicating the particular day they were to act as reviewers. After these activities, the same procedure used in data collection for the traditional model was employed. There was a positive correlation between the modern PE teaching model on self-motivation, as indicated in the graph in Figure 3. 


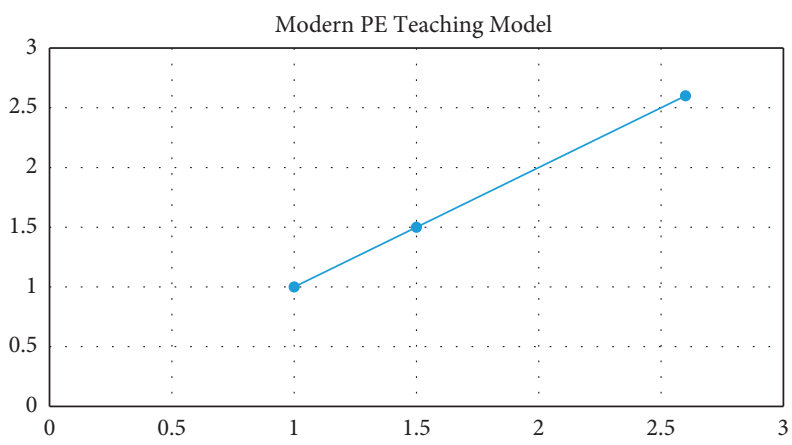

FIGURE 3: Relationship between new PE teaching models and autonomy, competence, motivation, and relatedness.

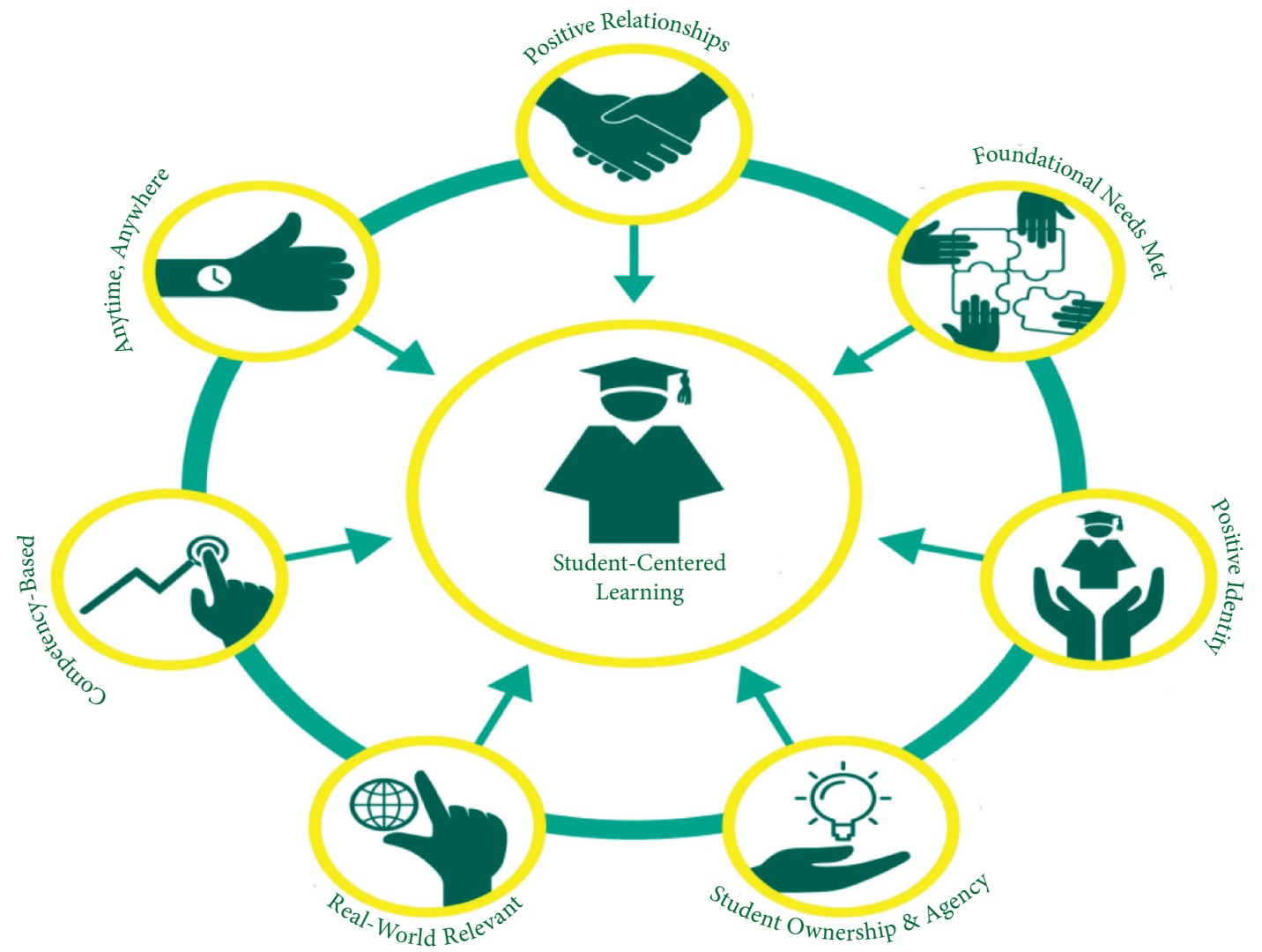

FIGURE 4: New model for teaching physical education.

Figure 3 indicates a positive correlation observed with the new physical education teaching model compared with the former traditional teaching model.

Traditional teaching models for physical education are not student-centered and thus lack self-motivation and selfdetermination. With these two essential qualities out of the way, many targets cannot be achieved with the traditional models in play. This is why modern student-centered approaches are the best. Current practices put the students at the center of everything, thus facilitating self-motivation and self-determination, leading to the continuous improvement of the activities in question. For instance, many students can be put off and therefore drop the lectures that they feel the teacher is at the center of everything. This is because it makes the lectures boring repetitive. Figure 4 shows the difference between the two models. For Figure 4, the student is at the center of everything. The student makes every decision, and the instructor acts as a facilitator. This model makes the students be self-driven and give them self-confidence.

It is believed and proven in several literary works that when anyone is asked for an opinion and their decisions upheld, there is an increase in their self-confidence. When an instructor is a pawn and controlling, he/she does not give the student a chance to make any decision. This may make them shy away from most of the activities or even drop the lectures in question. This should not be the case. As this applies to the learning process, it should also be the same for assessment processes. The instructor should not be the one to assess 
$100 \%$ of the activities done by the students; he should also give them a chance to evaluate themselves through peerreviews and rubrics. A student will grasp a concept more readily when delivered by another student than when an instructor provides it.

In the same way, a student will take correction positively from another peer than from a teacher. This is because there is no peer-to-peer inferiority complex as the instructors' superiority may intimidate them. With an excellent studentdriven model, many students will feel free to attend physical education lessons. This is because it will not seem more boring and repetitive, unlike in traditional models. It will be more fun and rejuvenating. Notwithstanding all the benefits derived from the instructor-teacher relationship, the students will also be able to maintain a healthy living and prevent the effects of LDL and TAGs [11] buildup, which will, in turn, control the contraction of CVD and NCDs. In contrast, maintaining and retaining sanity in LE as far as epidemiology are concerned [12-19].

\section{Conclusion}

In view of the problem, the traditional teaching mode is difficult to ensure mental and emotional health. In particular, lack of physical activity will not only have a direct and acute impact on individuals but also have an impact on the whole life cycle of individuals. This phenomenon occurs more in adolescents. This is because the traditional learning model is teacher-centered and lacks a good learning model. This paper improves the traditional teaching mode through the strategy of artificial intelligence, focuses on students, and increases students' physical exercise. In addition, a large number of experiments are carried out to verify the effectiveness and superiority of the algorithm proposed in this paper. It can provide some reference ideas for a large number of follow-up studies.

\section{Data Availability}

The data underlying the results presented in the study are included within the manuscript.

\section{Conflicts of Interest}

The author declares that there are no conflicts of interest in this paper.

\section{Authors' Contributions}

The author has seen the manuscript and approved to submit to your journal.

\section{References}

[1] V. N. P. Nandifa, Y. Jena, and S. Joewana, "Beneficence is the highest moral imperative of a doctor dealing with the poor quality of patient autonomy," Jurnal Pendidikan Kedokteran Indonesia: The Indonesian Journal of Medical Education, vol. 9, no. 1, pp. 44-51.
[2] P. M. Ferland, A. Pollock, R. Swope et al., "The relationship between physical characteristics and maximal strength in men practicing the back squat, the bench press and the deadlift," International Journal of Exercise Science, vol. 13, no. 4, pp. 281-297, 2020.

[3] A. N. Nasarudin, F. F. Sidek, and I. H. Shaari, "Prediction of quadriceps one repetition maximum (1RM) among novice lifters using 1RM equations," Health, vol. 3, no. 1, pp. 17-21, 2020.

[4] B. Koju, S. Chaudhary, A. Shrestha, and L. R. Joshi, "Cardiorespiratory fitness in medical students by queen's college step test: a cross-sectional study," Journal of Lumbini Medical College, vol. 7, no. 1, pp. 29-33, 2019.

[5] F. Azarian, S. Farsi, S. A. Hosseini, and M. A. Azarbayjani, "The effect of endurance training and crocin consumption on anxiety-like behaviors and aerobic power in rats with Alzheimer's," Iranian journal of psychiatry and behavioral sciences, vol. 13, no. 4, 2019.

[6] D. Deshmukh and J. Patel, "Research paper on bell curve method of performance management," International Journal of Management, vol. 10, no. 1, 2019.

[7] J. Diaz-Castro, P. J. Mira-Rufino, J. Moreno-Fernandez et al., "Ubiquinol supplementation modulates energy metabolism and bone turnover during high intensity exercise," Food \& Function, vol. 11, no. 9, pp. 7523-7531, 2020.

[8] R. Orr, V. Simas, E. Canetti, and B. Schram, "A profile of injuries sustained by firefighters: a critical review," International Journal of Environmental Research and Public Health, vol. 16, no. 20, p. 3931, 2019.

[9] T. A. C. Beach, D. M. Frost, J. D. Zehr, S. J. Howarth, S. M. McGill, and J. P. Callaghan, "Spine loading during laboratory-simulated fireground operations - inter-individual variation and method of load quantification," Ergonomics, vol. 62, no. 11, pp. 1426-1438, 2019.

[10] T. Andre, S. Valladao, S. Walsh, and D. Reisbeck, "Breathing limited air situational training masks (BlastMask) versus selfcontained breathing apparatus (SCBA) for firefighters: a Pilot study," International Journal of Exercise Science, vol. 12, no. 6, pp. 941-949, 2019.

[11] A. Le, L. A. McNulty, M.-A. Dyal, D. M. DeJoy, and T. D. Smith, "Firefighter overexertion: a continuing problem found in an analysis of non-fatal injury among career firefighters," International Journal of Environmental Research and Public Health, vol. 17, no. 21, Article ID 7906, 2020.

[12] J. Zhilyakova and M. Kostsova, "Viability as a factor of successful professional activity of firemen," in Recent Achievements and Prospects of Innovations and Technologies, pp. 546-551, International Journal of Environmental Research and Public Health, Russia, 2019.

[13] S. D. Flanagan, M. D. Mills, and A. J. Sterczala, "The relationship between muscle action and repetition maximum on the squat and bench press in men and women," The Journal of Strength \& Conditioning Research, vol. 28, 2014.

[14] K. Kim and Y. Park, "A development and application of the teaching and learning model of artificial intelligence education for elementary students," Journal of The Korean Association of Information Education, vol. 21, no. 1, pp. 139-149, 2017.

[15] T. Chen, N. Wang, R. Wang, H. Zhao, and G. Zhang, "Onestage CNN detector-based benthonic organisms detection with limited training dataset," Neural Networks, vol. 144, pp. 247-259, 2021.

[16] L. Chen, P. Chen, and Z. Lin, "Artificial intelligence in education: a review," IEEE Access, vol. 8, pp. 75264-75278, 2020. 
[17] X. Zhou, H. Xie, D. Zou, and G. J. Hwang, “Application and theory gaps during the rise of artificial intelligence in education," Computers and Education: Artificial Intelligence, vol. 1, Article ID 100002, 2020.

[18] D. Rodríguez-Rosell, J. Manuel Yáez García, and L. Sánchez Medina, "Relationship between velocity loss and repetitions in reserve in the bench press and back squat exercises," The Journal of Strength \& Conditioning Research: The Research Journal of the NSCA, vol. 34, pp. 2537-2547, 2020.

[19] C. Kyoungtaek, C. Myungsoo, and H. Chulsoo, Effects of Improve a Special Physical Strength to Muscular Training Program in Boxers, 2007. 